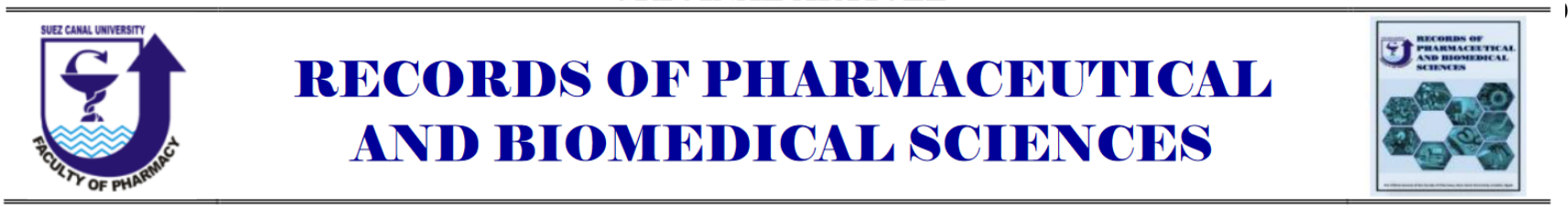

\title{
Synthesis and in silico studies of novel pyrazole-based anti-MERS-CoV agents
}

Marwa Elewa $^{\dagger 1}$, Mahitab Mohamed ${ }^{\dagger *}$, Mohamed S. Nafie ${ }^{3}$, Mohamed M. Said ${ }^{1}$, Adel Elgendy ${ }^{2}$ and Yasmine M. Abdel Aziz ${ }^{1}$

${ }^{1}$ Pharmaceutical Organic Chemistry Department, Faculty of Pharmacy, Suez Canal University, Ismailia, Egypt.

${ }^{2}$ Pharmaceutical Organic Chemistry Department, Faculty of Pharmacy, Misr international University, Obour, Egypt.

${ }^{3}$ Chemistry Department, Faculty of Science, Suez Canal University, Ismailia, Egypt.

†These authors contributed equally.

Received on: 20.04.2021

Revised on: 28.04.2021

Accepted on: 28.04.2021

*Corresponding author: mahitab09486@miuegypt.edu.eg

\begin{abstract}
Middle East respiratory syndrome coronavirus MERS-CoV represents a big challenge for the healthcare system all over the world. In the present study, five new compounds 4-8 were synthesized and investigated as anti-MERS-CoV agents. The structures of the new compounds 4-8 were justified by using micro-analytical and spectral data. Biological results showed that all the screened compounds might serve as promising anti-MERS-CoV agents. They showed $\mathrm{CC}_{50}$ ranging from $0.67 \mathrm{mM}$ to $3.22 \mathrm{mM}$. This range is superior to the standard antiviral agent Favipiravir with $\mathrm{CC}_{50}>400 \mathrm{mM}$. The most active compounds 4 and $\mathbf{6}$ were further subjected to Plaque Reduction assay. They showed a promising inhibitory pattern. In silico molecular modeling was performed for all the target compounds 4-8 inside the active site of COVID-19 main protease (PDB: 6LU7) to rationalize their antiviral activity. The substituted benzylidene carbohydrazide moiety of compounds 4-8 fits in the receptor cavity, which could explain the superior antiviral activity of the novel compounds $\mathbf{4 - 8}$.
\end{abstract}

Keywords: Pyrazole, MERS-CoV, main protease, 6LU7 and COVID-19. 


\section{Introduction}

The coronavirus disease-2019 (COVID-19) represents a worldwide life-threatening danger (Perlman 2020, Pilkington, Pepperrell et al. 2020, Zhang, Wu et al. 2020). Middle East Respiratory Syndrome MERS-CoV, severe acute respiratory syndrome coronavirus SARS$\mathrm{CoV}$ and severe acute respiratory syndrome coronavirus-2 SARS-CoV-2 belong to the family of Coronaviridae. The mortality rate of MERS-CoV is about $40 \%$. This rate is higher than SARS-CoV that is estimated to be $15 \%$ (Zaher, Mostafa et al. 2020).

Generally, coronaviruses are single-stranded enveloped RNA viruses. They have the largest known RNA virus genomes. The active sites of both SARS-CoV-2 and MERS-CoV conserve a great extent of structural similarity. The replication of coronavirus may be controlled by inhibiting protease enzyme. The coronavirus main protease is totally different from human proteases. Therefore, it is considered an encouraging target for designing antiviral agents (Ullrich and Nitsche 2020).

Favipiravir may act as COVID-19 main protease inhibitor and may further be used in the treatment of COVID-19 infection in a few countries, wherein it is approved (Cai, Yang et al. 2020, Chen, Huang et al. 2020). Favipiravir is a pyrazine carboxamide derivative that was discovered by Toyama Chemical Co., Ltd. (Furuta, Komeno et al. 2017). In 2014, it was approved in Japan for the treatment of the pandemic infections of influenza viruses (Hayden and Shindo 2019, Shiraki and Daikoku 2020). In 2020, the antiviral activity of Favipiravir was assessed for the emergency treatment of COVID-19 in different countries (Li and De Clercq 2020). Recently, Wang et al. reported that Favipiravir has half-cytotoxic concentration $\left(\mathrm{CC}_{50}\right)>400 \mathrm{mM}$ and a wellcharacterized safety profile (Pilkington, Pepperrell et al. 2020, Wang, Cao et al. 2020, Wang, Fan et al. 2020).

Herein, we investigate the antiviral activity of novel pyrazole-based analogues bearing a phenyl ring on the pyrazole nitrogen $\mathrm{N} 1$. The carboxamide moiety of Favipiravir was modified in our target compounds to a substituted benzylidene carbohydrazide moiety. These substituents might recognize new binding regions in the main protease active site,

\section{Figure 1.}

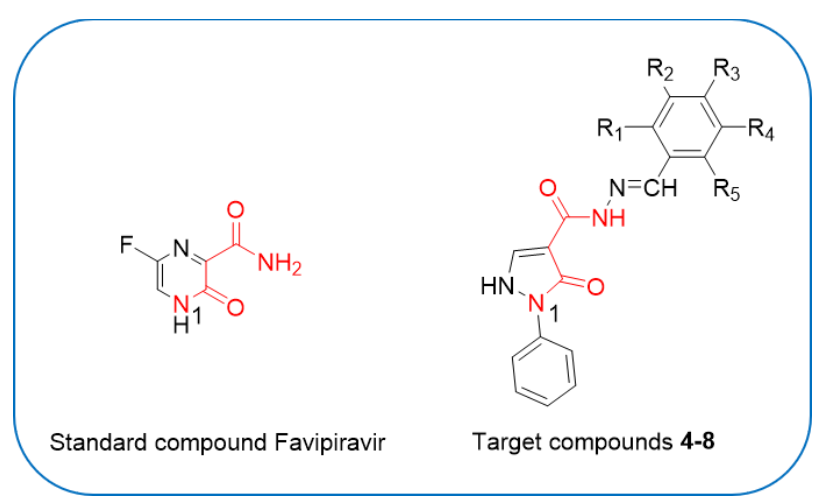

Figure 1. The design of antiviral agents. 


\section{Experimental}

\subsection{Materials and methods for synthesis and} analytical characterization

"All reagents were purchased from Aldrich, Merck and Fluka and were used without any further purification. Melting points were measured on an electrothermal apparatus in open capillary tubes using Stuart melting point apparatus SMP10 and were uncorrected. Infrared (IR) spectra were measured using $\mathrm{KBr}$ discs on a Vector 22 Infrared spectrophotometer $\left(v_{\max }\right.$ in $\left.\mathrm{cm}^{-1}\right)$, with ratio (1drug: $3 \mathrm{KBr}$ ). Nuclear Magnetic Resonance spectra were recorded on Bruker spectrometer $(400 \mathrm{MHz})$. Electron impact mass spectra (EI-MS) were recorded on a Finnigan MAT 312 mass spectrometer connected with a MASPEC Data System. Elemental analyses were performed in the Microanalytical center, Al Azhar University, Egypt”.

\section{Ethyl 3-oxo-2-phenyl-2,3-dihydro-1H-} pyrazole-4-carboxylate 2

Phenyl hydrazine $(0.1 \mathrm{~mol})$ was added to diethylethoxymethylene malonate (DEEM) (0.1 $\mathrm{mol})$ and $10 \%$ ethanolic $\mathrm{KOH}(10 \mathrm{ml})$. The mixture was refluxed for 40 mins at $80{ }^{\circ} \mathrm{C}$. The solution was poured on ice and a precipitate was formed. The collected precipitate was dissolved in $\mathrm{H}_{2} \mathrm{O}$ then neutralized with $10 \% \mathrm{HCl}$. The solid was recrystallized from ethanol (Das, Verma et al. 2008). White crystals; yield 95\%; m.p. $\left(118-120{ }^{\circ} \mathrm{C}\right)$.

\section{3-Oxo-2-phenyl-2,3-dihydro-1H-pyrazole-4-} carbohydrazide 3

Hydrazine monohydrate $80 \%(0.1 \mathrm{~mol})$ was added to compound $2(0.1 \mathrm{~mol})$ then refluxed in ethanol $(20 \mathrm{ml})$ for $2 \mathrm{hrs}$. The reaction was monitored by TLC. Upon completion, the reaction mixture was cooled and the formed precipitate was filtered, washed with water and recrystallized from ethanol to yield compound $\mathbf{3}$ (Karrouchi, Charkaoui et al. 2013). Yellow crystalline solid; yield 90\%; m.p. (165-167) ${ }^{\circ} \mathrm{C}$.

\section{(E)-N'-(substitutedbenzylidene)-3-oxo-2-}

\section{phenyl-2,3-dihydro-1H-pyrazole-4-}

\section{carbohydrazide 4-8}

A mixture of compound $3(0.1 \mathrm{~mol})$ and different aldehydes $(0.1 \mathrm{~mol})$ were dissolved in ethanol $(20 \mathrm{ml})$ in the presence of catalytic amount of glacial acetic acid. The reaction mixture was refluxed for 3-4 hrs. The reaction was monitored by TLC. Upon completion, the reaction mixture was poured on ice and a precipitate was formed. The formed precipitate was filtered, washed with water and recrystallized from ethanol to yield compounds 4-8 (Karrouchi, Charkaoui et al. 2013).

\section{(E)-N'-(4-chlorobenzylidene)-3-oxo-2-}

phenyl-2,3-dihydro-1H-pyrazole-4-

\section{carbohydrazide 4}

White crystals; yield $76 \%$; m.p. (204-206) ${ }^{\circ} \mathrm{C}$; IR $\left(\mathrm{KBr}, \mathrm{cm}^{-1}\right): 3557,3048,2996,1637,1485$; EI-MS (m/z，\%): $340\left(\mathrm{M}^{+}\right), 342\left(\mathrm{M}^{+}+2\right)$; 
${ }^{1} \mathrm{H}-\mathrm{NMR}$ (400MHz) (DMSO): $\delta_{\mathrm{H}} 8.72$ (s, 2H), 7.93-7.95 (dd, $\left.{ }^{2} J=8 \mathrm{~Hz}, 2 \mathrm{H}\right), 7.90-7.92$ (dd, $\left.{ }^{2} J=8 \mathrm{~Hz}, 2 \mathrm{H}\right), 7.60$ (s, 2H), 7.56-7.60 (m, 5H); Anal.Calcd. for $\mathrm{C}_{17} \mathrm{H}_{13} \mathrm{ClN}_{4} \mathrm{O}_{2}$ : C, 59.92; H, 3.85 N, 16.44. Found: C, 59.68; H, 4.18; N, 16.28 .

(E)-N'-(4-hydroxybenzylidene)-3-oxo-2-

phenyl-2,3-dihydro-1H-pyrazole-4carbohydrazide 5

Yellow crystals; yield $68 \%$; m.p. $(212-214){ }^{\circ} \mathrm{C}$; IR (KBr, cm $\left.{ }^{-1}\right): 3425,3010,2990,1710,1635$, 1428; EI-MS (m/z, \%): $322\left(\mathrm{M}^{+}\right)$; ${ }^{1} \mathrm{H}-\mathrm{NMR}$ (400MHz) (DMSO): $\delta_{\mathrm{H}} 11.15(\mathrm{~s}, 1 \mathrm{H}), 9.00(\mathrm{~s}$, 2H), 7.68-7.70 (dd, $\left.{ }^{2} J=8 \mathrm{~Hz}, 2 \mathrm{H}\right), 7.41-7.43$ (dd, $\left.{ }^{2} J=8 \mathrm{~Hz}, 2 \mathrm{H}\right), 7.39$ (s, 2H), 6.96-7.99 (m, 5H); ${ }^{13} \mathrm{C}-\mathrm{NMR}$ (DMSO-d6): $\delta_{\mathrm{C}} 116.99,118.63$, $120.11, \quad 131.33, \quad 133.74, \quad 159.07, \quad 163.27$; Anal.Calcd. for $\mathrm{C}_{17} \mathrm{H}_{14} \mathrm{~N}_{4} \mathrm{O}_{3}$ : C, 63.35; $\mathrm{H}, 4.38$; N, 17.38. Found: C, 62.86; H, 4.68; N, 17.20.

\section{(E)-N'-(2-hydroxybenzylidene)-3-oxo-2-}

\section{phenyl-2,3-dihydro-1H-pyrazole-4-}

\section{carbohydrazide 6}

Yellow crystals; yield $70 \%$; m.p. (212-214) ${ }^{\circ} \mathrm{C}$; IR (KBr, cm$\left.{ }^{-1}\right): 3425,3167,3047,2954,1712$, 1622, 1413; EI-MS (m/z, \%): $322\left(\mathrm{M}^{+}\right)$; ${ }^{1} \mathrm{H}-\mathrm{NMR}$ (400MHz) (DMSO): $\delta_{\mathrm{H}} 11.15$ (s, 1H), $9.00(\mathrm{~s}, 2 \mathrm{H}), 7.69-7.88(\mathrm{~m}, 4 \mathrm{H}), 7.52(\mathrm{~s}, 2 \mathrm{H})$, 6.94-7.41 (m, 5H); Anal.Calcd. for $\mathrm{C}_{17} \mathrm{H}_{14} \mathrm{~N}_{4} \mathrm{O}_{3}$ : C, 63.35; H, 4.38; N, 17.38. Found: C, 63.26; H, 4.70; N, 17.59 .
(E)-N'-(3,5-dichloro-2-hydroxybenzylidene)3-oxo-2-phenyl-2,3-dihydro-1H-pyrazole-4carbohydrazide 7

White crystals; yield $67 \%$; m.p. $(270-272)^{\circ} \mathrm{C}$. IR $\left(\mathrm{KBr}, \mathrm{cm}^{-1}\right)$ : 3448, 3170, 3070, 2924, 1712, 1627, 1458; EI-MS (m/z, \%): $390\left(\mathrm{M}^{+}\right), 391$ $\left(\mathrm{M}^{+}+1\right) ;{ }^{1} \mathrm{H}-\mathrm{NMR}(400 \mathrm{MHz})(\mathrm{DMSO}): \delta_{\mathrm{H}} 12.49$ (s, 1H), 9.08 (s, 2H), 7.88 (s, 2H), $7.80(\mathrm{~s}, 2 \mathrm{H})$, 7.32-7.77 (m, 5H); ${ }^{13} \mathrm{C}-\mathrm{NMR}$ (DMSO-d6): $\delta_{\mathrm{C}}$ 122.47, 126.69, 127.26, 127.82, 130.03, 138.23, 139.58, 155.18, 162.95, 164.04; Anal.Calcd. for $\mathrm{C}_{17} \mathrm{H}_{12} \mathrm{Cl}_{2} \mathrm{~N}_{4} \mathrm{O}_{3}$ : C, 52.19; H, 3.09; N, 14.32. Found: C, 52.40; H, 3.29; N, 14.18.

(E)-N'-(2-nitrobenzylidene)-3-oxo-2-phenyl2,3-dihydro-1H-pyrazole-4-carbohydrazide 8 Yellowis white crystals; yield $75 \%$; m.p. (212214) ${ }^{\circ} \mathrm{C}$; IR $\left(\mathrm{KBr}, \mathrm{cm}^{-1}\right): 3448,3101,2924$, 1751, 1651, 1527, 1442, 1342; EI-MS (m/z, \%): $351\left(\mathrm{M}^{+}\right)$; ${ }^{1} \mathrm{H}-\mathrm{NMR}(400 \mathrm{MHz})$ (DMSO): $\delta_{\mathrm{H}}$ 8.97 (s, 2H), 8.15-8.18 (m, 5H), 7.90 (s, 2H), 7.78-7.82 (m, 4H); Anal.Calcd. for $\mathrm{C}_{17} \mathrm{H}_{13} \mathrm{~N}_{5} \mathrm{O}_{4}$ : C, 58.12; H, 3.73; N, 19.93. Found: C, 58.34; H, 3.89; N, 20.11.

\subsection{Biological evaluation}

\subsubsection{MTT cytotoxicity assay}

"The cytotoxic activities of the extracts were tested in Vero E6 cells by using the 3-(4, 5dimethylthiazol -2-yl)-2, 5-diphenyltetrazolium bromide (MTT) method. The percentage of cytotoxicity compared to the untreated cells was determined with the following equation" (Mosmann 1983). 
The plot of \% cytotoxicity versus sample concentration was used to calculate the concentration which exhibited 50\% cytotoxicity $\left(\mathrm{CC}_{50}\right) "$

$\%$ cytotoxicity

(absorbance of cells without treatment - absorbance of cells with treatment $) X 100$

\subsubsection{Plaque reduction assay for screening of anti-MERS Corona activity}

"Assay was carried out according to the reported method (Hayden, Cote et al. 1980) in a six well plate where Vero E6 cells $\left(10^{3}\right.$ cells / $\left.\mathrm{ml}\right)$ were cultivated for $24 \mathrm{hrs}$ at $37{ }^{\circ} \mathrm{C}$. The virus was diluted to give countable plaques at dilution $10^{5}$ and mixed with the safe concentration of the tested extracts based on the cytotoxicity assay and incubated for 1 hour at $37{ }^{\circ} \mathrm{C}$ before being added to the cells. Control wells were included where untreated virus was incubated with Vero E6 cells and finally plaques were counted and percentage reduction in plaques formation in comparison to control wells was determined as following:"

Viral inhibition $\%=\frac{\text { Viral count untreatment }- \text { viral count treatment }}{\text { Viral count untreatment }} \times 100$

\subsection{Molecular docking study}

The molecular docking study of the target compound 4-8 and Favipiravir (Silva Arouche, Reis et al. 2020) was carried out in the COVID-19 main protease active site (PDB=6LU7) (Jin, Du et al. 2020). The protein structure optimization as well as chemical and energetic optimization of the investigated compounds 4-8 were performed as reported by Nafie et al (Nafie, Tantawy et al. 2019). The molecular docking calculations were validated using MOE 2019. The analysis of drug target interaction was visualized by Chimera software.

\section{Results and discussion}

\subsection{Chemistry}

Scheme 1 illustrated the synthetic route developed for the synthesis of target compounds 4-8. These compounds were synthesized via the simplest and the most economic chemical pathway.
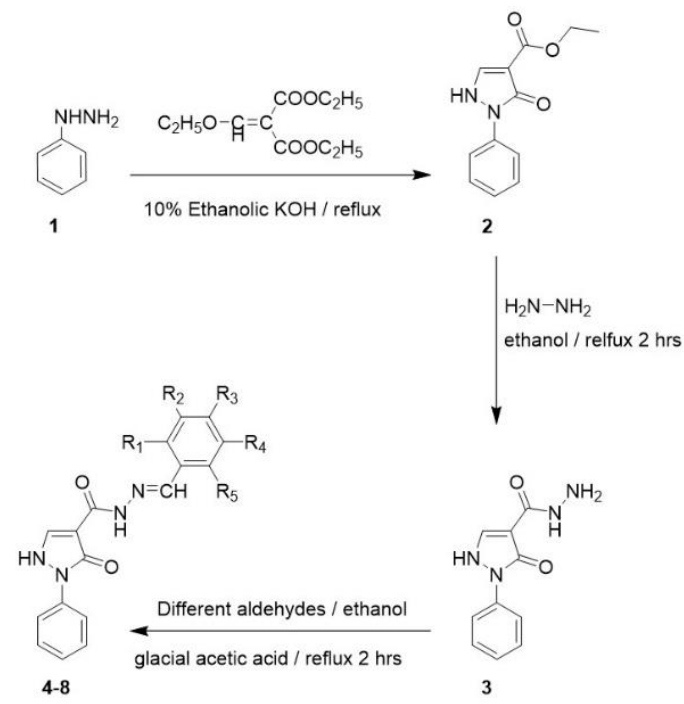

\begin{tabular}{cccccc}
\hline Cpd. & $\mathbf{R}_{\mathbf{1}}$ & $\mathbf{R}_{\mathbf{2}}$ & $\mathbf{R}_{\mathbf{3}}$ & $\mathbf{R}_{\mathbf{4}}$ & $\mathbf{R}_{\mathbf{5}}$ \\
\hline $\mathbf{4}$ & $\mathrm{H}$ & $\mathrm{H}$ & $\mathrm{Cl}$ & $\mathrm{H}$ & $\mathrm{H}$ \\
5 & $\mathrm{H}$ & $\mathrm{H}$ & $\mathrm{OH}$ & $\mathrm{H}$ & $\mathrm{H}$ \\
$\mathbf{6}$ & $\mathrm{OH}$ & $\mathrm{H}$ & $\mathrm{H}$ & $\mathrm{H}$ & $\mathrm{H}$ \\
7 & $\mathrm{OH}$ & $\mathrm{Cl}$ & $\mathrm{H}$ & $\mathrm{Cl}$ & $\mathrm{H}$ \\
$\mathbf{8}$ & $\mathrm{NO}_{2}$ & $\mathrm{H}$ & $\mathrm{H}$ & $\mathrm{H}$ & $\mathrm{H}$ \\
\hline
\end{tabular}

Scheme 1. Synthesis of target compounds 4-8.

Microanalyses and spectral data (IR, ${ }^{1} \mathrm{H}-\mathrm{NMR},{ }^{13} \mathrm{C}-\mathrm{NMR}$ and EI-MS) were used to 
elucidate the structure of the synthesized compounds 4-8. The IR spectra showed collectively $\mathrm{NH}$ and $\mathrm{C}=\mathrm{O}$ stretching at around $3300-3500 \mathrm{~cm}^{-1}$ and 1630-1700 $\mathrm{cm}^{-1}$ respectively, the appearance of $\left(\mathrm{Ar}-\mathrm{H}, \mathrm{sp}^{2}\right)$ stretching at $3000-3100 \mathrm{~cm}^{-1},(=\mathrm{C}-\mathrm{H})$ stretching at $3010-3100 \mathrm{~cm}^{-1},(\mathrm{~N}-\mathrm{C}=\mathrm{O})$ at around 1665 $1710 \mathrm{~cm}^{-1}$. Furthermore, the IR spectra of compounds 5, 6 and 7 showed $(\mathrm{O}-\mathrm{H})$ stretching at $3200-3400 \mathrm{~cm}^{-1}$ and compound 8 showed strong stretching related to $(\mathrm{N}-\mathrm{O}$, nitro) at 1527 and $1342 \mathrm{~cm}^{-1}$. ${ }^{1} \mathrm{H}-\mathrm{NMR}$ spectra of the newly synthesized compounds 4-8 showed NH singlets at $\delta_{\mathrm{H}}[8.72-9.20 \mathrm{ppm}]$ in addition to aromatic multiplets at $\delta_{\mathrm{H}}$ [6.96-8.17 ppm]. Regarding the ${ }^{1} \mathrm{H}-\mathrm{NMR}$ spectra of compounds 5, 6 and 7, singlets at $\delta_{\mathrm{H}}$ [11.00-12.49 ppm] were detected that referred to the hydroxyl group $(\mathrm{OH})$.

\subsection{Biological activity}

The antiviral activities of the target compounds 4-8 were evaluated against MERS-CoV. The results were listed in Table 1.

Table 1. The antiviral activities of target compounds 4-8 against MERS-CoV.

\begin{tabular}{cc}
\hline Cpd. & $\mathrm{CC}_{50} \mathrm{mM}$ \\
\hline $\mathbf{4}$ & 0.77 \\
$\mathbf{5}$ & 9.00 \\
$\mathbf{6}$ & 0.67 \\
$\mathbf{7}$ & 3.22 \\
$\mathbf{8}$ & 1.99 \\
Favipiravir & $>400$ \\
\hline
\end{tabular}

All the screened compounds 4-8 might serve as promising antiviral agents. They showed $\mathrm{CC}_{50}$ ranging from $0.67 \mathrm{mM}$ to $3.22 \mathrm{mM}$. This range is superior to the standard antiviral agent Favipiravir with $\mathrm{CC}_{50}>400 \mathrm{mM}$ (Pilkington, Pepperrell et al. 2020).

The most active compounds $\mathbf{4}$ and $\mathbf{6}$ were further subjected to Plaque Reduction assay. A plaqueforming unit (PFU) is a measure used in virology to describe the number of virus particles capable of forming plaques per unit volume (Hayden, Cote et al. 1980). Compounds 4 and 6 showed promising viral inhibitory patterns in the Plaque Reduction assay. The results are listed in Table 2.

\subsection{In silico studies}

\subsubsection{Molecular Modeling}

To highlight the virtual mechanism of binding for the tested compounds $\mathbf{4 - 8}$, they were screened for their binding ability towards the COVID-19 main protease highlighting both binding energy and the drug-target interactions. As seen in Figure 2, the peptide-like inhibitor forms three interactions with the key amino acids Glu 166, Gln 189 and Thr 190 with bond length ( 2 A). From the docking study, the tested compounds 4-8 were docked inside the COVID-19 main protease active site with good binding energy from $-18.03 \mathrm{Kcal} / \mathrm{mol}$ to -21.03 $\mathrm{Kcal} / \mathrm{mol}$ and their interactions with the key amino acids were listed in Table 3 . 
Table 2. Viral activity for Middle East Respiratory Syndrome (MERS-CoV) evaluated by Plaque Reduction assay.

\begin{tabular}{|c|c|c|c|c|}
\hline Cpd. & $\begin{array}{l}\text { Concentration } \\
\mathrm{mg} / \mathrm{ml}\end{array}$ & $\begin{array}{c}\text { Virus control } \\
\text { (PFU/ml) }\end{array}$ & $\begin{array}{c}\text { Viral count after } \\
\text { treatment } \\
(\mathrm{PFU} / \mathrm{ml})\end{array}$ & Viral Inhibition $\%$ \\
\hline \multirow{4}{*}{4} & 0.054 & \multirow{4}{*}{$2.8 * 10^{5}$} & $2.4 * 10^{5}$ & 14.2 \\
\hline & 0.027 & & $2.5^{*} 10^{5}$ & 10.7 \\
\hline & 0.013 & & $2.7 * 10^{5}$ & 3.5 \\
\hline & 0.006 & & $2.8 * 10^{5}$ & 0 \\
\hline \multirow{4}{*}{6} & 0.43 & \multirow{4}{*}{$2.8 * 10^{5}$} & toxic & 0 \\
\hline & 0.22 & & toxic & 0 \\
\hline & 0.22 & & toxic & 0 \\
\hline & 0.05 & & $1.5^{*} 10^{5}$ & 46.4 \\
\hline
\end{tabular}

Interestingly, compounds 4-8 like the Favipiravir, formed two strong hydrogen bond interactions with Glu 166 through the carbonyl group as HBA and with Gln 189 through the NH-group as HBD. This is a good rationalization that the tested compounds 4-8 have the same active pharmacophoric region of the carboxamide group like Favipiravir. Unlike Favipiravir, substituted benzylidene carbohydrazide moiety of the target compounds 4-8 fits plausibly in the receptor cavity and extended deep in the characteristic pocket formed by Gln 192, Thr 190, His 164, Gly 143 and Ala 193. This finding could explain the superior antiviral activity of the novel compounds 4-8.

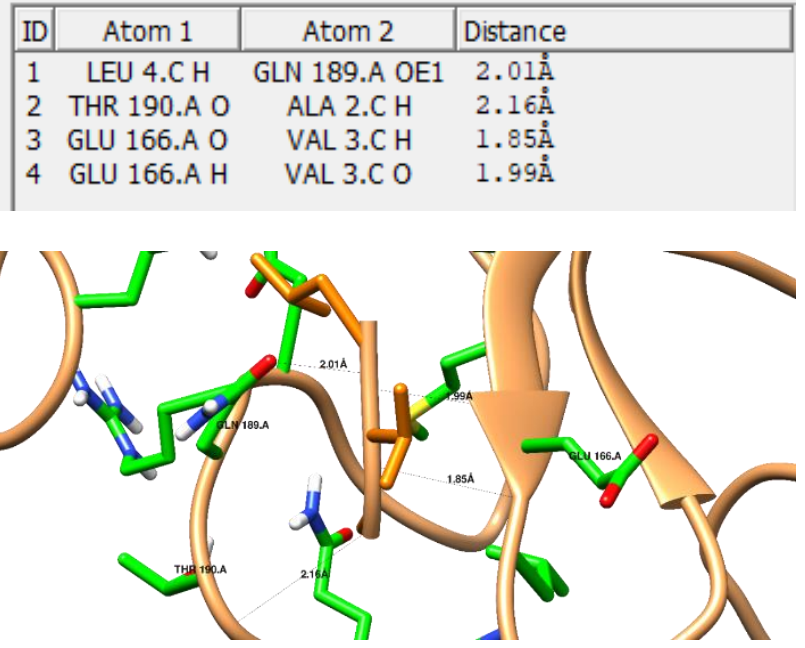

Figure 2. Binding disposition and active site of peptide-like inhibitor (Chain C, Orange), inside the COVID-19 main protease (Chain A, Buff), with highlighted key residues; Gln 189, Glu 166, and Thr 190 (Green). 
Table 3. Summary of ligand-receptor interactions of the docked compounds inside the active site of COVID-19 main protease (PDB: 6LU7).

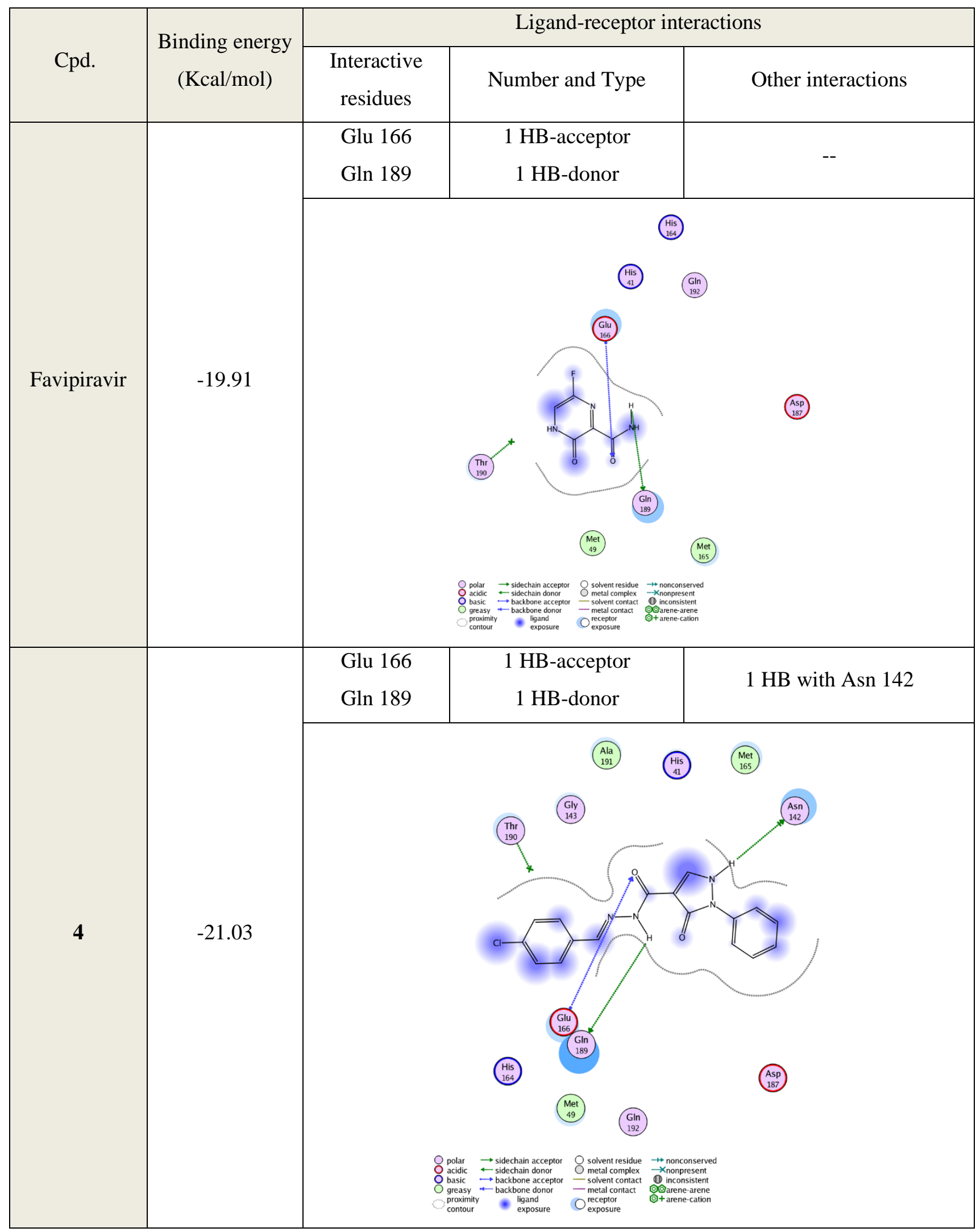




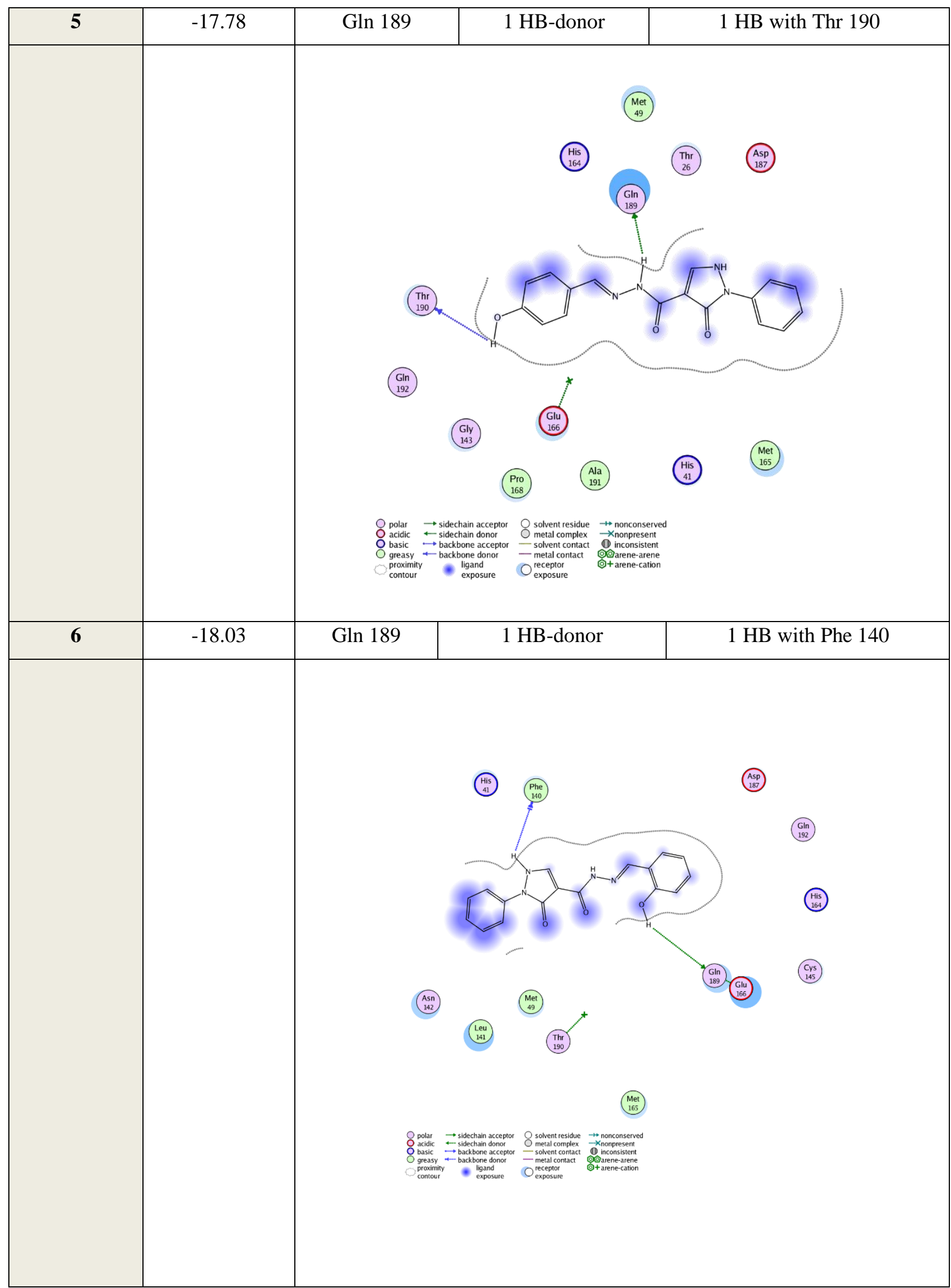


Rec. Pharm. Biomed. Sci. 5(1), 121-134, 2021

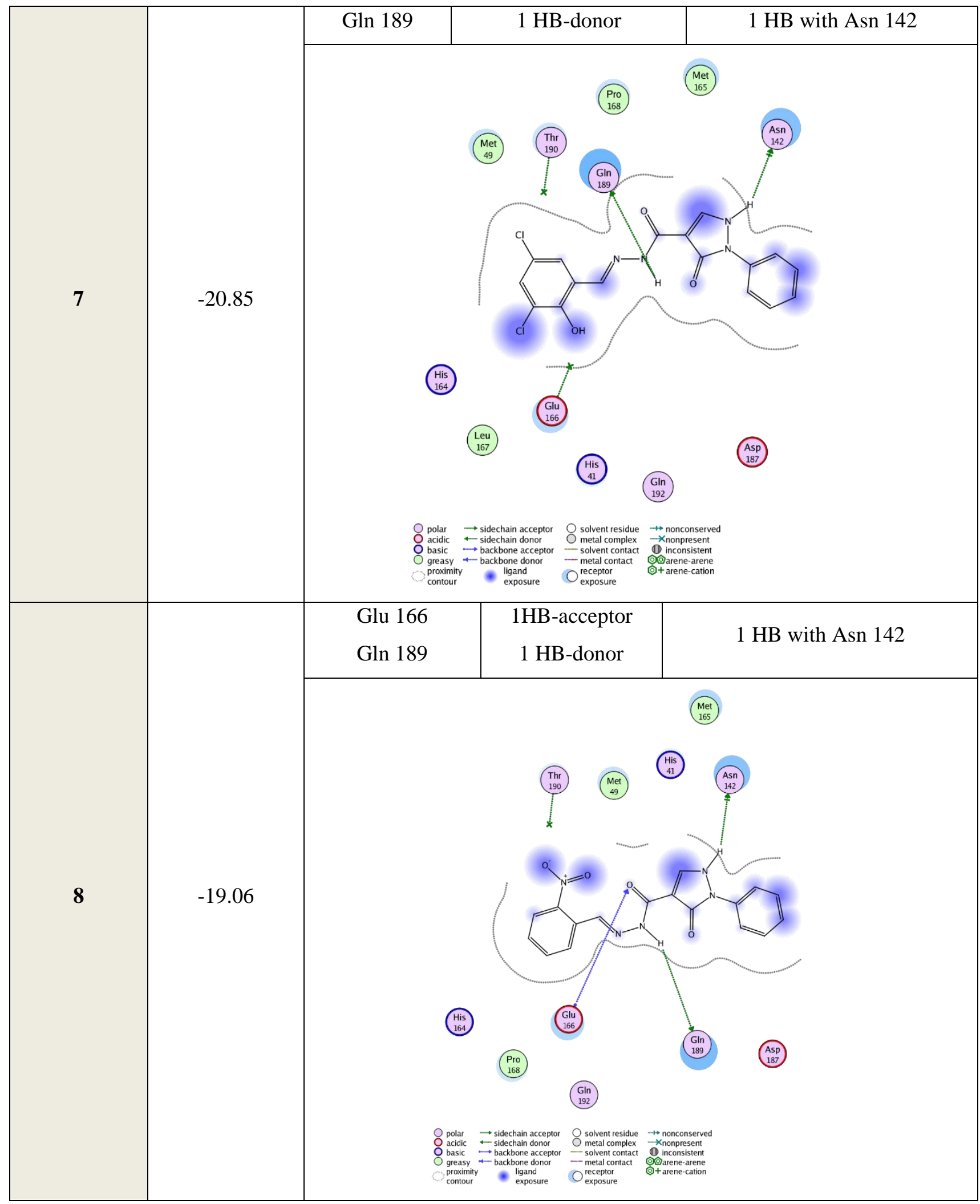

*Docking calculation using MOE-2019 was validated by having the RMSD value lower than two. 
Table 4. In silico ADME pharmacokinetics properties of tested compounds 4-8.

\begin{tabular}{|c|c|c|c|c|c|c|c|c|c|c|}
\hline \multirow[t]{2}{*}{ Cpd. } & \multicolumn{6}{|c|}{$\begin{array}{l}\text { Molinspiration } 2018.10 \\
\text { (Tantawy, Amer et al. 2020, Youssef, El-Moneim et al. } \\
\text { 2020) }\end{array}$} & \multicolumn{3}{|c|}{$\begin{array}{c}\text { MolSoft } \\
\text { (Nafie, Amer et al. 2020) }\end{array}$} & \multirow{2}{*}{$\begin{array}{c}\text { SwissADME } \\
\text { (Daina, } \\
\text { Michielin et al. } \\
\text { 2017) } \\
\text { Drug likeness } \\
\text { (Lipinski Pfizer } \\
\text { filter) }\end{array}$} \\
\hline & $\begin{array}{l}\text { MWt } \\
\text { (D) }\end{array}$ & $\begin{array}{l}\text { MV } \\
\left(\mathrm{A}^{3}\right)\end{array}$ & $\begin{array}{l}\text { PSA } \\
\left(\mathrm{A}^{2}\right)\end{array}$ & $\log p$ & nrotb & nviolations & HBA & HBD & $\begin{array}{l}\text { Solubility } \\
\text { (mg/L) }\end{array}$ & \\
\hline 4 & 340.77 & 284.38 & 79.26 & 2.88 & 4 & 0 & 3 & 2 & 159.47 & \multirow{5}{*}{$\begin{array}{l}\text { "Yes, drug like" } \\
\mathrm{MW} \leq 500, \mathrm{Log} \\
\mathrm{p} \leq 4.15, \mathrm{HBA} \leq \\
10 \text { and } \mathrm{HDD} \leq 5\end{array}$} \\
\hline 5 & 322.32 & 278.86 & 99.49 & 1.72 & 4 & 0 & 4 & 3 & 3007.67 & \\
\hline 6 & 322.32 & 278.86 & 99.49 & 2.14 & 4 & 0 & 4 & 3 & 632.48 & \\
\hline 7 & 391.21 & 305.93 & 99.49 & 3.19 & 4 & 0 & 4 & 3 & 152.40 & \\
\hline 8 & 351.32 & 294.18 & 125.0 & 2.11 & 5 & 0 & 5 & 2 & 293.7 & \\
\hline
\end{tabular}

"Mwt: Molecular Weight, MV: Molecular Volume, PAS: Polar Surface Area, Log p: Log P: Octanol-water partition coefficient, nrotb: number of rotatable bond, nviolations: number of violations, HBA: Hydrogen Bond Acceptor, HBD: Hydrogen Bond Donor"

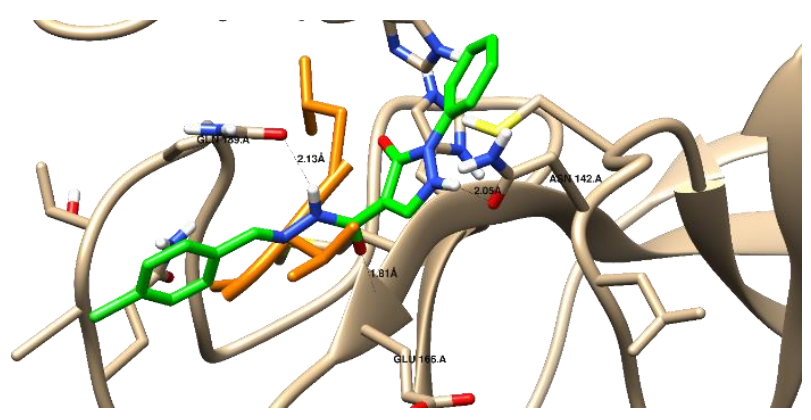

Figure 3. Binding dispoition of docked compound 4 (Green), and the peptide-like inhibitor (Orange) inside the COVID-19 main protease with the 3D-visualization of interactions.

\section{Bioinformatics study}

All the tested compounds were tested for physicochemical properties and drug-like properties using Bioinformatics studies. For the future drug candidates with Lipinski's (Ro5) (Lipinski 2004). For good drug absorbance through intestines, the values of topological polar surface area (TPSA) must be as low as 140 and the blood brain barrier (BBB) must be as low as $90 \AA^{2}$ (Clark and Pickett 2000). The compounds 4-8 were all well-permeable and well-absorbed. As shown in Table 4, compounds 4-8 had 2-3 donors and 3-5 acceptors for hydrogen bonding. Besides, all tested compounds 4-8 exhibited $\log \mathrm{P}$ values between 2.11 and 3.74 , so they were well tolerated by cell membranes. For controlling conformational changes and oral bioavailability, 
the rotatable bond number (nrotb) should be $\leq$ 10 (Veber, Johnson et al. 2002), all the tested compounds 4-8 had 4-5 nrotb. Additionally, all the tested compounds 4-8 exhibited good druglikeness score using Swiss ADME, especially the lead compound $\mathbf{4}$, with drug-likeness score of 0.81 using MolSoft as shown in Figure 4.

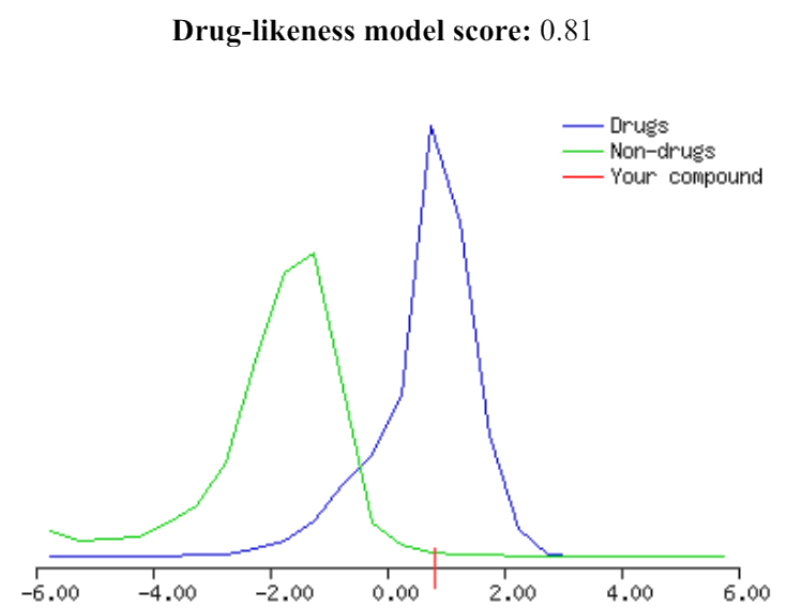

Figure 4. Plot of Drug likeness score for the compound $4 \quad(\mathbf{0 . 8 1})$ using Molsoft. Blue-colored curve for drug like behavior, and green-colored curve for non-drug like behavior.

\section{Conclusion}

Middle East respiratory syndrome coronavirus MERS-CoV represents a major growing public healthcare problem all over the world. Herein, we investigate the anti MERS-CoV activity of novel pyrazole-based analogues bearing a phenyl ring on the pyrazole nitrogen N1. The carboxamide moiety of Favipiravir was modified in our target compounds to a substituted benzylidene carbohydrazide moiety.
The target compounds $\mathbf{4 - 8}$ displayed $\mathrm{CC}_{50}$ ranging from $0.67 \mathrm{mM}$ to $3.22 \mathrm{mM}$, which is superior to the standard antiviral agent Favipiravir with $\mathrm{CC}_{50}>400 \mathrm{mM}$. Molecular modeling and bioinformatics were performed for all the newly synthesized compounds 4-8 inside the active site of COVID-19 main protease (PDB: 6LU7). Like Favipiravir, compounds 4-8 formed two strong hydrogen bond interactions with the key amino acids inside the active site. Unlike Favipiravir, substituted benzylidene carbohydrazide moiety of the target compounds 4-8 extended deeply in the characteristic pocket of COVID-19 main protease. This might explain the superior activity of our target compounds. Moreover, all the tested compounds exhibited good druglikeness score using SwissADME, especially the lead compound $\mathbf{4}$, with drug-likeness score of 0.81 using MolSoft.

\section{Acknowledgments}

We would like to thank Prof. Dr. Mohamed A. A. Ali, Ph.D. Director of Center of Scientific Excellence for Influenza Viruses, National Research Centre, 12311 Dokki, Giza for the biological evaluation. The authors declare no potential conflicts of interest. This study did not receive any grant from funding agencies in the commercial, public, or not-for-profit sectors.

\section{References}

Cai, Q., M. Yang, D. Liu, J. Chen, D. Shu, J. Xia, X. Liao, Y. Gu, Q. Cai and Y. Yang (2020). 
"Experimental treatment with favipiravir for COVID-19: an open-label control study." Engineering 6(10): 1192-1198.

Chen, C., J. Huang, Z. Cheng, J. Wu, S. Chen, Y. Zhang, B. Chen, M. Lu, Y. Luo and J. Zhang (2020). "Favipiravir versus arbidol for COVID19: a randomized clinical trial." MedRxiv.

Clark, D. E. and S. D. Pickett (2000). "Computational methods for the prediction of 'drug-likeness'." Drug discovery today 5(2): 4958.

Das, N., A. Verma, P. K. Shrivastava and S. K. Shrivastava (2008). "Synthesis and biological evaluation of some new aryl pyrazol-3-one derivatives as potential hypoglycemic agents."

Furuta, Y., T. Komeno and T. Nakamura (2017). "Favipiravir (T-705), a broad spectrum inhibitor of viral RNA polymerase." Proceedings of the Japan Academy, Series B 93(7): 449-463.

Hayden, F. G., K. Cote and R. G. Douglas (1980). "Plaque inhibition assay for drug susceptibility testing of influenza viruses." Antimicrobial agents and chemotherapy 17(5): 865-870.

Hayden, F. G. and N. Shindo (2019). "Influenza virus polymerase inhibitors in clinical development." Current opinion in infectious diseases 32(2): 176.

Jin, Z., X. Du, Y. Xu, Y. Deng, M. Liu, Y. Zhao, B. Zhang, X. Li, L. Zhang and C. Peng (2020). "Structure of $\mathrm{M}$ pro from SARS-CoV-2 and discovery of its inhibitors." Nature 582(7811): 289-293.

Karrouchi, K., Y. Charkaoui, K. Benlafya, Y. Ramli, J. Taoufik, S. Radi and M. Ansar (2013). "Synthesis, characterization and preliminary biological activity of some new pyrazole carbohydrazide derivatives." J. Chem. Pharm. Res 5(3): 1-6.

Li, G. and E. De Clercq (2020). "Therapeutic options for the 2019 novel coronavirus (2019nCoV)." Nature reviews Drug discovery 19(3): 149-150.

Lipinski, C. A. (2004). "Lead-and drug-like compounds: the rule-of-five revolution." Drug Discovery Today: Technologies 1(4): 337-341.

Mosmann, T. (1983). "Rapid colorimetric assay for cellular growth and survival: application to proliferation and cytotoxicity assays." Journal of immunological methods 65(1-2): 55-63.

Nafie, M. S., M. A. Tantawy and G. A. Elmgeed (2019). "Screening of different drug design tools to predict the mode of action of steroidal derivatives as anti-cancer agents." Steroids 152: 108485.

Perlman, S. (2020). Another decade, another coronavirus, Mass Medical Soc.

Pilkington, V., T. Pepperrell and A. Hill (2020). "A review of the safety of favipiravir-a potential treatment in the COVID-19 pandemic?" Journal of virus eradication 6(2): 45-51.

Shiraki, K. and T. Daikoku (2020). "Favipiravir, an anti-influenza drug against life-threatening RNA virus infections." Pharmacology \& therapeutics 209: 107512.

Silva Arouche, T. d., A. F. Reis, A. Y. Martins, J. F. S Costa, R. N. Carvalho Junior and A. M. JC Neto (2020). "Interactions Between Remdesivir, Ribavirin, Favipiravir, Galidesivir, Hydroxychloroquine and Chloroquine with Fragment Molecular of the COVID-19 Main Protease with Inhibitor N3 Complex (PDB ID: 6LU7) Using Molecular Docking." Journal of Nanoscience and Nanotechnology 20(12): 7311-7323.

Ullrich, S. and C. Nitsche (2020). "The SARSCoV-2 main protease as drug target." Bioorg Med Chem Lett 30(17): 127377.

Veber, D. F., S. R. Johnson, H.-Y. Cheng, B. R. Smith, K. W. Ward and K. D. Kopple (2002). "Molecular properties that influence the oral bioavailability of drug candidates." Journal of medicinal chemistry 45(12): 2615-2623.

Wang, M., R. Cao, L. Zhang, X. Yang, J. Liu, M. Xu, Z. Shi, Z. Hu, W. Zhong and G. Xiao (2020). "Remdesivir and chloroquine effectively inhibit the recently emerged novel coronavirus (2019-nCoV) in vitro." Cell research 30(3): 269-271.

Wang, Y., G. Fan, A. Salam, P. Horby, F. G. Hayden, C. Chen, J. Pan, J. Zheng, B. Lu and L. Guo (2020). "Comparative effectiveness of combined favipiravir and oseltamivir therapy versus oseltamivir monotherapy in critically ill patients with influenza virus infection." The 
Journal of infectious diseases 221(10): 16881698.

Zaher, N. H., M. I. Mostafa and A. Y. Altaher (2020). "Design, synthesis and molecular docking of novel triazole derivatives as potential
CoV helicase inhibitors." Acta Pharmaceutica 70(2): 145-159.

Zhang, T., Q. Wu and Z. Zhang (2020). "Probable pangolin origin of SARS-CoV-2 associated with the COVID-19 outbreak." Current biology 30(7): 1346-1351. e1342. 